\title{
A dual de-icing system for wind turbine blades combining high-power ultrasonic guided waves and low-frequency forced vibrations
}

\author{
Hossein Habibi', Liang Cheng, Haitao Zheng, Vassilios Kappatos, Cem Selcuk, Tat-Hean Gan \\ Brunel Innovation Centre (BIC), Brunel University, Uxbridge, Middlesex, UB8 3PH, United Kingdom
}

\begin{abstract}
Wind turbines mounted on cold climate sites are subject to icing which could significantly influence the performance of the turbine blades for harvesting wind energy. In this study, an innovative dual de-icing system under development is described. This either prevents ice accumulation (anti-icing) or removes any ice layer present on the surface of the blade material (de-icing). A modelling study on ultrasonic guided waves propagating in composite blades was used to determine the optimal frequency and location of the transducers for ensuring wave propagation, causing the required level of energy concentration and resulting shear stress across the leading edge of the turbine's blade. In parallel, the effects of low frequency vibrations have been investigated through modal and harmonic analyses. This allowed specification and optimisation of the positioning of shaker(s), together with the magnitude and direction of harmonic forces required to induce sufficient acceleration to the blade surface for ice removal. An appropriate survey was also carried out to evaluate the potential for fatigue failure of the blade due to harmonic forces induced by shakers. The proposed technique configures and presents an active solution for the icing problem, allowing safe and reliable operation of wind turbines in adverse weather conditions.
\end{abstract}

Keywords: Wind turbine blades, de-icing, ultrasonic guided waves, low frequency vibration, fatigue

\section{Introduction}

Nowadays wind energy is one of the leading renewable energy sources. An important issue is the location of sites which are sufficiently windy to gain maximum efficiency. However many areas offering high potential for harvesting wind energy are exposed to low temperature over winter and this, together with the resultant icing, affects the operational performance of wind turbines. One of the major problems is ice accretion on turbine blades which produces significant change in the aerodynamic geometry of the blade's surface. As a result, it can considerably reduce the efficiency of wind turbines. Furthermore, icing can cause imbalance in blades leading to increased wear in structural components such as connectors, couplers, gearbox etc. Safety hazards may also result, especially in residential areas, as large pieces of ice may be thrown from turbine blades during operation. In extreme cases, turbine operation may have to be halted until weather conditions become suitable, affecting overall energy production.

To alleviate the above-mentioned problems raised by ice formation on turbine blades a number of techniques have been developed and tested to anti-ice and/or de-ice the blades. Methods in current use include surface coating, antifreeze chemicals, electrical resistance heating, hot air circulation, pulse electrothermal de-icing, manual chip-off, etc. However there are drawbacks and limitations for the full industrial uptake of these methods. For example,

\footnotetext{
${ }^{1}$ Corresponding author; emails: hossein.habibi@brunel.ac.uk, bic@brunel.ac.uk, Tel: +44(0)1223 899079
} 
chemicals do not remain on the blade surfaces for a long time period and even coated surfaces cannot effectively prevent ice formation [1]. Also all existing thermal de-icing methods demand a high level of power to operate. Consumed power may reach $12 \%$ and $15 \%$ of the turbine's nominal power output in the cases of electrical resistance heating and hot air circulation respectively [2]. Apart from the issue of energy consumption, the high temperature induced in the blade by thermal techniques may pose a serious risk for the integrity of composite blades [2]. Other developing methods such as microwave heating have either poor performance or low energy efficiency [3]. The drawbacks and limitations of existing ice control approaches indicate the potential for development of a new reliable and cost-effective de-icing technology.

A relatively new strategy used for ice protection systems is ultrasonic guided waves (UGW) for which a few research projects have recently been reported [4-6]. This method is well known for non-destructive testing applications in which the waves propagate in a low frequency range (typically between 20 and $100 \mathrm{kHz}$ for long-range ultrasonic testing). Based on wave theory, ultrasonic waves cause displacements and stresses inside a material as they propagate through it. Therefore they have the potential for removing ice accumulated on different surfaces. For example, Venna et al [7] applied ultrasonic waves of $1 \mathrm{kHz}$ frequency on an aluminium airfoil structure which matched its resonance frequency and de-iced the airfoil. They could manage to shed off the ice 130 seconds after excitation of piezoelectric excitation patches. The shear and normal stresses measured during their experiment for achieving this reached $7.5 \mathrm{MPa}$ and 25 MPa respectively. JL Palacios [8] tested ultrasound waves for helicopter blade anti-icing and deicing using two distinct modes: transverse and shear, which were effective on leading edges at both short range and over longer distances. For short distances near the transducers, de-icing results were excellent using ultrasound powers of up to $0.37 \mathrm{~W} / \mathrm{cm}^{2}$ which is very energy efficient compared with thermal ice protection systems. Part of the current research has been built on this previous research.

Another technique associated with the current work is low-frequency vibrations whose background dates back to 1978 when Bell Helicopter performed a feasibility study on the application of mechanical vibrations to prevent ice accretion on helicopter blades [9]. In that research, an electric motor was used to vibrate a helicopter's main blade in beamwise and/or torsional modes close to the blade's major natural frequencies to induce maximum excited energy into its structure. It was found that harmonic forces generating acceleration of 25 to $30 \mathrm{~g}$ at a low frequency range between 0 and $50 \mathrm{~Hz}$ could lead to satisfactory de-icing. Results for deicing of the helicopter blade proved to be more effective in the most critical areas of the blade near to the hub while being less efficient at the leading edge. However, for wind turbines, the leading edge of the blade is of high importance for de-icing or protection against freezing [5, 9]. Hence the dual system which has been studied here combines low frequency vibrations and ultrasonic waves in an attempt to provide total blade coverage. An efficient de-icing system that does not impair structural integrity while providing deicing for the entire structure of the blades is desirable. For this reason, in parallel with deicing potential, the potential reduction of the blade's life due to fatigue effects has to be considered.

\section{Current vibratory deicing approaches}

\subsection{Overview}

As mentioned above, earlier attempts to deice helicopter blades have shown that lowfrequency vibrations are highly effective in de-icing across the blades except at the leading edges, whilst the application of ultrasound (US) have been proved to be very good at de-icing merely at surfaces such as the leading edge of the blade where the US power density is high. Hence the present work, as its main innovation, combines these two techniques, so that one subsystem will compensate for the deficiencies of the other. This approach provides sufficient 
energy induced to the blades through both internally exciting particles of the material and externally shaking the whole structure. In the former case, wave propagation towards the leading edge causes the shear stress required to break the ice-substrate bond while in the latter, acceleration generated in the blade causes the ice to be shaken off. The system is estimated to consume low power to fulfil these tasks, which is another advantage. This point will be briefly explained in the sample results.

The present work focused on modelling to develop a reliable ice protection system for antiicing and/or de-icing wind turbine blades. Simulation plays a crucial role in designing the system as it should verify that the waves can propagate through a composite blade. Also the harmonic forces and the locations of the shakers need to be determined to check whether or not they can generate sufficient acceleration in the critical areas of the blade without causing serious damage. The fatigue life of the blade due to low-frequency vibrations caused by shakers is potentially significant and should be investigated. In fact, since the first mode shapes of the blade structure particularly with frequencies below $50 \mathrm{~Hz}$ are crucially important, previous studies on the fatigue analysis of wind turbine blades have been mainly based on these frequencies (see, for example, $[10,11,12])$. Fatigue analysis in the current work has been carried out for different scenarios in forced vibrations to confirm that the new approach does not endanger wind turbine blade structural integrity.

Figure 1 outlines the steps taken in developing the ice protection system in the current work. The relevant details for each term along with modelling procedure are presented in the following sections.

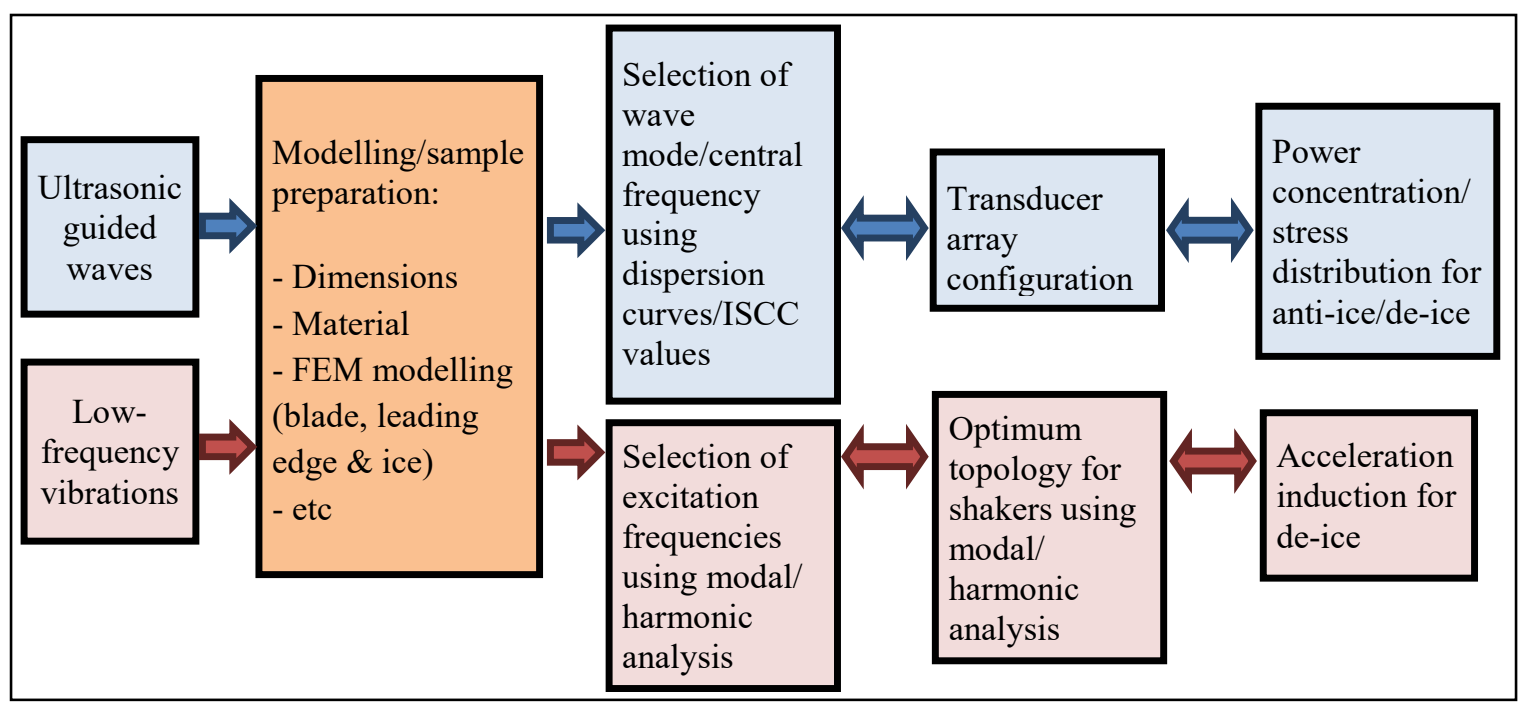

Fig. 1: Flowchart of measures taken for de-icing/anti-icing the wind turbine blade

\subsection{Ultrasonic guided waves}

Preliminary research on helicopter blade de-icing via ultrasonic guided waves was carried out by Palacios et al $[8,13]$. The idea is the induction of shear stress in such a way that interfacial stress between ice and substrate exceeds the adhesion strength between them. However the question was how to generate such a stress that exceeds the bond strength while reducing the inplane shear stress inside the substrate to avoid any damage to the blade. The resolution found for this challenge was presented through the concept of Interfacial Stress Concentration Coefficients (ISCC) to calculate the normalized interface shear stress for different combinations of ultrasonic guided wave modes and frequencies [4]. In fact, ISCC is a value used for assessing the capability to induce enough stress into the interface for a given amount of power. In other words, ISCC is a normalized value to optimize frequency, mode and power for generating maximum interface 
shear stress. For this reason, the current work considers this value as one of the main criteria in the following analyses and simulations regarding ultrasonic guided waves. Therefore dispersion curves with ISCC were first calculated to investigate the best frequency and wave mode, then an analysis of power concentration and stress distribution was conducted.

By modelling the complex vibration modes present in the different sample configurations, it was possible to determine a dispersion curve and predict the dispersive properties of each blade configuration or plate structure to a reasonable level of accuracy. This was performed using eigenfrequency and time dependent analysis in the structural mechanics module. An eigenfrequency analysis is an effective tool for describing natural behaviour for a structural geometry when resonating. In addition, time dependent analysis was used to investigate the transient power and stress distribution and ultrasound propagation generated from transducer arrays.

An eigenfrequency analysis based on FEM provided the mode shape and natural frequency information. Two critical parameters were still required in order to plot a dispersion curve: phase velocity and wavelength. Wavelength could be determined by observing the mode shape for each eigenfrequency. Wavelength defines the distance travelled by a complete wave (1 peak and 1 trough), and the phase velocity at that frequency could therefore be calculated using the following equation.

$$
\lambda=\frac{L}{n}, v_{p}=\lambda f
$$

where $L$ is the length of the geometry being modelled (e.g. leading edge of the blade) and $n$ is the number of complete cycles observed from the mode shape.

To calculate the number of cycles, a 1D plot of the mode shape variation along the central line of the leading edge was produced (see Fig. 5 for the studied central line on the blade leading edge). The data extracted here were post-processed using a script which loaded and plotted the total displacement variation data, and counted the number of peaks and troughs for each wave mode for the entire range of eigenfrequencies. Using this information, the number of cycles was calculated using the following formula:

$$
n=\frac{N_{\text {of }} \text { peaks }+N_{\text {of }} \text { troughs }}{2}
$$

Once the number of cycles had been calculated, the wave length for that mode and its phase velocity was also calculated, and a phase velocity dispersion curve was generated. The maximum of the mesh size is normally less than $1 / 10$ of the wavelength at the frequency of interest, and the mesh size was set as $2 \mathrm{~mm}$ in the model. Also the Interface Stress Concentration Coefficient (ISCC) is defined by the following equation when the axis $x$ is the direction of wave propagation

$$
I S C C=\frac{\left.\sigma_{y z}\right|_{\text {layer interface }}}{\sqrt{\text { power }}}
$$

where $\sigma_{y z}$ is the component of stress tensor in yz plane at the interface between sample and ice, and power is defined by the following equation when $z$ is the direction along thickness

$$
\text { power }=\int_{\text {thickness }} P_{x} d z
$$

where $P$ is the Poynting's vector defining the power flow on the structure and $\mathrm{P}=\left[P_{x}, P_{y}, P_{z}\right]$. The parameter $P$ governs the equation below:

$$
P=\frac{-\vec{v}^{*} \cdot \sigma}{2}
$$

where $\vec{v}$ is particle velocity, ${ }^{*}$ is the complex conjugate and $\sigma$ is the stress tensor. 


\begin{tabular}{|c|c|c|c|c|c|c|c|c|c|}
\hline $\begin{array}{c}\text { Mechanical } \\
\text { properties }\end{array}$ & $\begin{array}{c}E_{1} \\
(\mathrm{GPa})\end{array}$ & $\begin{array}{c}E_{2} \\
(\mathrm{GPa})\end{array}$ & $\begin{array}{c}E_{3} \\
(\mathrm{GPa})\end{array}$ & $\begin{array}{c}G_{12} \\
(\mathrm{GPa})\end{array}$ & $\begin{array}{c}G_{13} \\
(\mathrm{GPa})\end{array}$ & $\begin{array}{c}G_{23} \\
(\mathrm{GPa})\end{array}$ & $v_{23}$ & $v_{12}$ & $v_{13}$ \\
\hline STEF-1 glass fabric & 5.62 & 4.59 & 4.59 & 0.406 & 0.406 & 0.28 & 0.24 & 0.22 & 0.22 \\
\hline
\end{tabular}

The ISCC is a measurement of how much shear stress can be produced at the interface between ice and substrate for a given produced power per metre. When the interface shear stress exceeds the adhesive shear strength of ice to the sample surface, de-icing will be achieved. The larger the ISCC, the less ultrasonic power is required to generate blade cleaning. Large ISCC points on the dispersion curves show large normalised interface shear stress rather than large physical stresses at the ice interface. A minimisation in the required excitation power could be achieved by considering a point on the dispersion curves with a large ISCC value, providing the sensor is available for resonating at the same frequency. The criteria for selecting the central frequency and wave mode for ultrasonic de-icing are: a) The larger the ISCC, the less power would be required for the de-icing system to be effective, $b$ ) the central frequency and wave mode should be non-dispersive. In the Results section, the dispersion curve and ISCC for a composite blade with varying thickness of glaze ice (one of the most common types of ice formed on blades) are calculated and optimised central frequency, phase velocity and wave length of ultrasonic wave are selected according to the criteria above.

\subsection{FEM model}

Finite Element Methods (FEM) based on numerical solutions of Partial Differential Equations (PDEs) offer a method for finding approximate numerical solutions of the natural frequencies of vibration and the mode shape as well as the propagation of ultrasound. The solution approach involves either eliminating the differential equations completely (steady state problems) or rendering the PDEs into an approximating system of ordinary differential equations, which are then solved numerically by integration using standard techniques such as Euler's method.

The current case study was selected as a 7.5-m composite blade of a V-15 wind turbine with $75 \mathrm{~kW}$ power generation. This turbine uses blades of a basic NACA 44xx airfoil series [14]. All the geometrical details and physical properties of this blade can be found in [10] and [14]. Figure 2(a) shows a view of the blade's cross sectional areas, with some parts of the shell surface removed to display the internal spar-box construction. In this figure, the three main parts of the blade's body namely skin, spar (shear webs) and caps are indicated. They were modelled with different thickness of $0.007 \mathrm{~m}, 0.009 \mathrm{~m}$ and $0.0156 \mathrm{~m}$ respectively. Figure 2(b) shows a representation of the created FEM model. The orthotropic mechanical properties of glassreinforced composite utilised for the blade structure in the simulated model are given in Table 1. The density of this composite material was $\rho=1860 \mathrm{~kg} / \mathrm{m}^{3}$ and its damping coefficient approximately $\zeta=0.003[15]$.

Table 1: Mechanical properties of fiberglass composite used in the blade model 


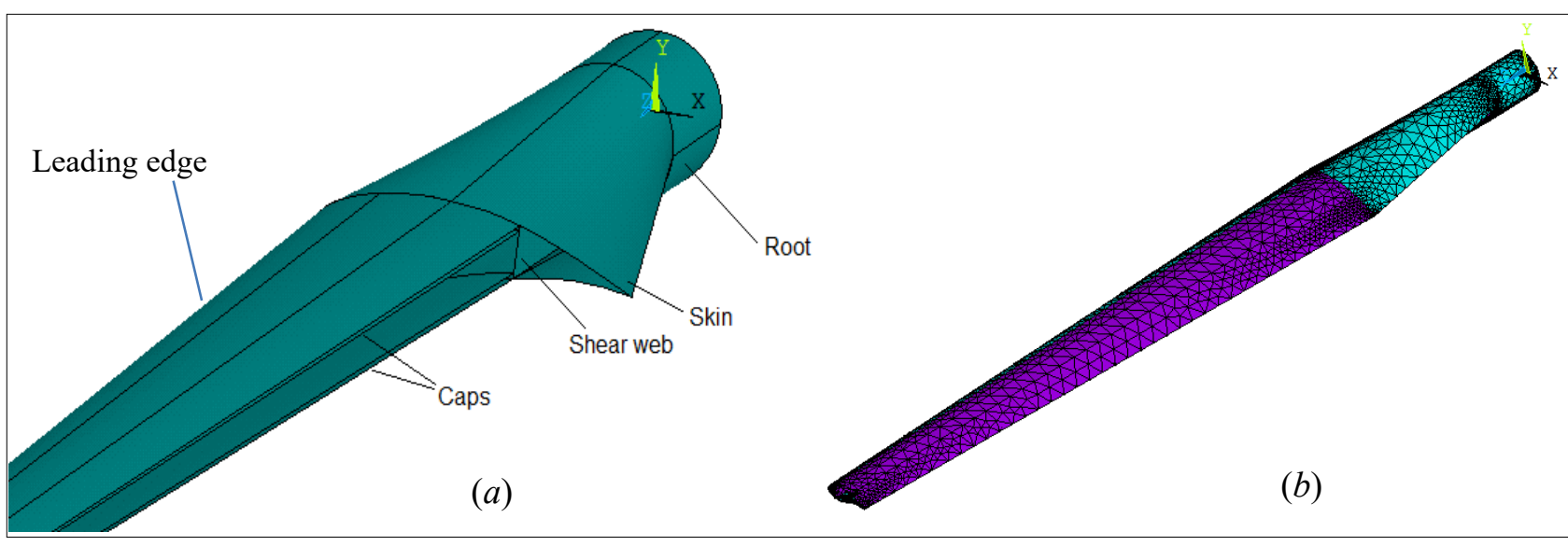

Fig. 2: The wind turbine blade modelled in ANSYS a) a cross section area in the widest part of the blade, b) A representation of the whole FEM model

In the structure of a typical wind turbine blade, the root joint is usually metallic while it is covered by composite laminates internally and externally. The main body of the blade is then screwed to the hub through this strong root. This means that the root could act as a clamping wall for the rest of the blade with regard to its stiffness and all its six degrees of freedom are constrained. In the current study, the blade root was considered to be 6063-T5 aluminium alloy with the following properties: Young's modulus elasticity: $68.9 \mathrm{GPa}$, Poisson's Ratio: 0.33 , shear modulus: $25.8 \mathrm{GPa}$, density: $2700 \mathrm{~kg} / \mathrm{m}^{3}[16,17]$.

The 3-D model was completed by creating surfaces which were then meshed via element SHELL181. This element is suitable for analysing thin to moderately-thick shell structures. It is a four-node element with six degrees of freedom at each node. SHELL181 is commonly used for layered applications for modelling composite shells or sandwich construction and therefore complies with the requirements of the current case. Since this element had to be used for different parts of the blade with different thickness and material, a lay-up was applied through sectioning the shell. It was then possible to allocate the correspondent properties to every part i.e. root, skin, shear webs and caps. Mesh congestion was increased in some edges or lines at which the slope of surfaces changed. A refinement study was then conducted to show that the model mesh size was sufficient for convergence. Finally a satisfactorily accurate model was built up using 16688 shell elements.

\subsection{Low-frequency vibrations}

The aim of applied low frequency vibration is to induce the largest acceleration possible into the blade, so as to prevent building up or induce cracking and detachment of ice. Exciting the structure close to one of its major resonance frequencies will produce a large vibration. So the resonant frequencies of the blade and the structure's response were investigated. However, exciting a structure too close to its resonant frequency could damage it. Therefore potential effects on fatigue life of the blade were studied to determine the tolerable stress range, whether yield or fatigue stress, that could be produced by the vibrators. The optimum topology of vibrators based on modal analysis of the blade and application criteria such as maximum induced acceleration were also determined.

\subsubsection{Modal analysis}

Having completed the model, its dynamical behaviour had to be studied and verified. Since the model developed here is similar to the case studied by Movaghghar and Lvov [10], the 
dynamical characteristics of these two models were comparable. For this reason, a modal analysis was carried out to obtain the natural frequencies and mode shapes of the model.

Solving the general equation of motion of a structure with a negligible damping leads to an eigenvalue problem as follows:

$$
\left|[K]-\omega^{2}[M]\right|=0
$$

This is an eigenvalue problem which may be solved for up to $n$ values of $\omega^{2}$ and $n$ eigenvectors $\left\{\emptyset_{i}\right\}$ which satisfy Eq. (6) where $n$ is the number of DOFs. The natural frequencies are output:

$$
f_{i}=\frac{\omega_{i}}{2 \pi}
$$

where $f_{i}$ is the $i_{\text {th }}$ natural frequency.

Each eigenvector $\left\{\varnothing_{i}\right\}$ can be normalized as the following:

$$
\{\phi\}_{i}^{T}[M]\{\phi\}_{i}=1
$$

The eigenvectors $\left\{\varnothing_{i}\right\}$ represent the mode shapes - the shape assumed by the structure when vibrating at frequency $f_{i}$.

In this work, modal analysis was performed using the created FEM model. To solve the classic eigenvalue Eq. (6), the Block Lanczos Method was used to solve the eigenvalue problem in this task. The Block Lanczos eigenvalue solver uses the Lanczos algorithm where the Lanczos recursion is performed with a block of vectors. The Block Lanczos method is especially powerful when searching for eigenfrequencies in a given part of the eigenvalue spectrum of a given system.

\subsubsection{Harmonic analysis}

In this section, the structural responses at frequencies in the frequency band of interest were calculated and the spectrum graphs of response versus frequency plotted quantitatively. The harmonic analysis assumed that the applied loads and the steady-state response varied sinusoidally (harmonically) with time. The time-dependent equations of motion are given by:

$$
[M]\{\ddot{u}\}+[C]\{\dot{u}\}+[K]\{u\}=\left\{F^{a}\right\}
$$

All points in the structure are moving at the same known frequency, but not necessarily in phase. It is also known that the presence of damping [C] causes phase shifts. Therefore, the displacement $\{\mathrm{u}\}$ can be defined as:

$$
\{u\}=\left\{u_{\max } e^{i \emptyset}\right\} e^{i \omega t}
$$

Substituting Equation (10) into (9), the dependence on time $e^{i \omega t}$ on both sides of the equation could be removed. Therefore, the general equation of motion of a system subjected to external harmonic force could be simplified and presented as a complex equation of harmonic motion as the following:

$$
\left(-\omega^{2}[M]+i \omega[C]+[K]\right)\left(\left\{u_{1}\right\}+i\left\{u_{2}\right\}\right)=\left\{F_{1}\right\}+i\left\{F_{2}\right\}
$$

where $\left\{F_{1}\right\}$ and $\left\{F_{2}\right\}$ are the real and imaginary parts of the force vector respectively and $\{u\}$ stands for nodal displacement vector.

Using the full method provided in ANSYS, harmonic analysis was performed over a frequency range [ 050$] \mathrm{Hz}$. In this study, the damping ratio was set as $0.3 \%$, which is based on damping characteristics identified from comprehensive experiments carried out by Larwood etc. [15]. However aerodynamic damping was not considered in this analysis. Dynamic responses of the blade to harmonic excitation for different arrangements of vibrators were investigated. Figure 
3 shows the potential places for shakers to be mounted on the blade. Section 3.2, Fig. 9, will demonstrate how these three points were chosen as potential locations.

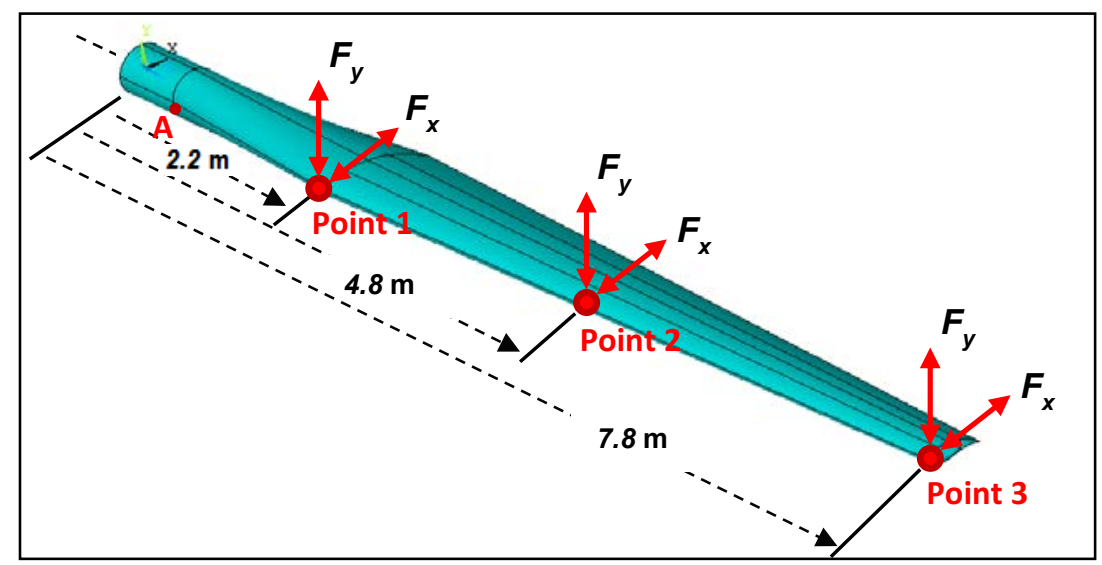

Fig. 3: Potential points for applying vibrator forces on the turbine blade

Two forces of $100 \mathrm{~N}, F_{\mathrm{x}}$ in $x$ direction and $F_{\mathrm{y}}$ in $y$ direction, were applied simultaneously to excite modes in both flapwise and edgewise directions. It should be mentioned that the forces were placed on the blade's edge at a point off the central, longitudinal axis in order to excite twisting modes apart from flexural bending in directions $x$ and $y$ and consequently maximise efficiency. The response thus included all the bending and torsional modes combined. Different scenarios for applying harmonic forces were tested as either an array of dual (i.e. points $1 \& 2$, $1 \& 3$ and $2 \& 3$ ) or single shakers and finally all three points simultaneously. Harmonic responses of the blade at three nodes, which are labelled as Point 1, Point 2 and Point 3 in Fig. 3 were investigated.

\subsection{Fatigue life approach}

It has been well reported that wind turbines are considered within the category of fatigue critical machines [17] and the design of many of their components (especially blades) is dictated by fatigue considerations. Fatigue failure of turbine blades has been investigated for various purposes and due to different types of loading [18-21]. The current work has performed a fatigue analysis subjected to external forced vibration for blade de-icing which makes the purpose of this life prediction distinct compared to previous work.

In an analytical fatigue approach developed recently, Movaghghar and Lvov [10] proposed an energy-based method for predicting fatigue life and evaluating progressive damage in a composite wind turbine blade. This work, regardless of yearly wind spectra and random statistical analysis, only considered maximum stress developed in the blade structure due to any imposed loading. The approach was found to be readily applicable to different systems (in terms of loading conditions) while not to be directly dependent on knowing yield stress or the static strength of material. Although the proposed formula needs two empirical constants, these were determined and characterized through a series of experimental fatigue test for 30 specimens cut in different directions from the blade. Full details on deriving the final approach can be found in reference 10. Finally the following equation was solved in order to determine the number of cycles to failure $\left(N_{f}\right)$ :

$$
N_{f}=1 /\left(\frac{m}{2^{n}}(n+1) \cdot\left(\sigma_{1}\left(\frac{\sigma_{1}}{E_{1}}-\frac{v_{21}}{E_{2}} \sigma_{2}\right)+\sigma_{2}\left(\frac{-v_{12}}{E_{1}} \sigma_{1}+\frac{\sigma_{2}}{E_{2}}\right)+\frac{\tau_{12}^{2}}{G_{12}}\right)^{n}\right)
$$

where $m$ and $n$ are the fixed parameters characterised through fatigue experiments as $\mathrm{m}=4.26^{*} 10^{-}$ ${ }^{25}(\mathrm{~Pa})^{-\mathrm{n}}$ and $\mathrm{n}=3.311$. 
The variables $\sigma_{1}, \sigma_{2}$ and $\tau_{12}$ are defined as the maximum principal stresses (normal and shear) that can have various values depending on loading characteristics. In each loading case FEM analysis results were obtained via ANSYS in order to be used in Eq. (12).

Wind turbines are subjected to different dynamic loads such as aerodynamic loads, changes in gravitational forces, changes in the wind direction, annual gust, centrifugal force, gyroscopic forces due to yaw movements and activation of mechanical brake almost all the time while the harmonic forced vibration caused by shakers will only be applicable occasionally for short periods during icing. The shakers should be triggered by ice detection system probably a few times a day during icing weather conditions depending on the rate of ice accumulation on the blade surface, working for approximately 2 seconds each time [9]. So additional impact on fatigue life caused by applied vibration is considered to be far smaller than what may be expected from other common load cases.

An acceptable normal fatigue life which is so called infinite life varies based on the type of application and material. In terms of GFRP material, there is a wide range of infinite fatigue life reported, varying from $10^{5}$ to $10^{8}$ cycles depending on the geometry of reinforcing fibres, lay-up configuration, laminate orientation, etc. [17]. Hence a number between $10^{6}-10^{7}$ cycles on average may be considered as a satisfactory range for the blade bearing in mind that shakers are supposed to work only for a very short period of time over a year. In addition, the intermittent application of harmonic forces on the blade would lead to a fatigue life higher than what are presented here due to possible stress relief between icing episodes.

\section{Sample numerical results}

\subsection{Ultrasonic guided waves}

A portion of the leading edge of a $7 \mathrm{~mm}$ thick composite blade with two different ice thicknesses $(0.5 \mathrm{~mm}$ and $2 \mathrm{~mm})$ was investigated. The boundary conditions for two edges of the blade were set as symmetric boundary conditions, where the ultrasound propagated through the boundaries without any reflection, as shown in Fig. 5. The anisotropic material properties of glass fibre are listed in Table 1, while the Young's modules, Poisson's ratio and density of the glaze ice are $8.3 \mathrm{GPa}, 0.351$ and $900 \mathrm{~kg} / \mathrm{m}^{3}$ respectively. The laminated structure of GFRP is simplified in this model with orthotropic Young's modules and Poisson's ratio tensors. As an example, the dispersion curve and ISCC results for a 2-mm ice layer are shown in Fig. 4. In the middle figure of ISCC against frequency, ISCC values are largest at 12.56 and $14.47 \mathrm{kHz}$ and relatively large at $7.94,13.02$, and $13.78 \mathrm{kHz}$. Combining these data with the dispersion curve, the frequencies at 7.94, 13.02, and $13.78 \mathrm{kHz}$ are dispersive. According to the criteria mentioned in Section 2.2, the optimised central frequency, phase velocity and wave length of ultrasonic wave for a $7 \mathrm{~mm}$ thick leading edge composite blade with $2 \mathrm{~mm}$ thick glaze ice were chosen as $12.56 \mathrm{kHz}, 1047 \mathrm{~m} / \mathrm{s}, 0.083 \mathrm{~m}$ respectively. Note that once frequency and wave mode have been chosen, the phase velocity can be worked out as a dependent parameter. The summary of results for the two different ice thicknesses is listed in Table 2.

Table 2: Summary of simulation results on selection of central frequency, phase velocity and wave length

\begin{tabular}{|c|c|c|c|}
\hline Optimised parameters & $\mathrm{F}_{\mathrm{c}}(\mathrm{kHz})$ & Phase velocity $(\mathrm{m} / \mathrm{s})$ & Wave length $(\mathrm{m})$ \\
\hline GFRP blade $+0.5 \mathrm{~mm}$ ice & 8.342 & 834 & 0.1 \\
\hline GFRP blade $+2 \mathrm{~mm}$ ice & 12.56 & 1047 & 0.083 \\
\hline
\end{tabular}

The following work regarding power focus via transducer array is based on the values given in Table 2. The excitation frequency follows the values for different thickness of ice; the time 
period for simulation is dependent on phase velocity and the distance between ultrasonic transducers which is determined by wavelength.
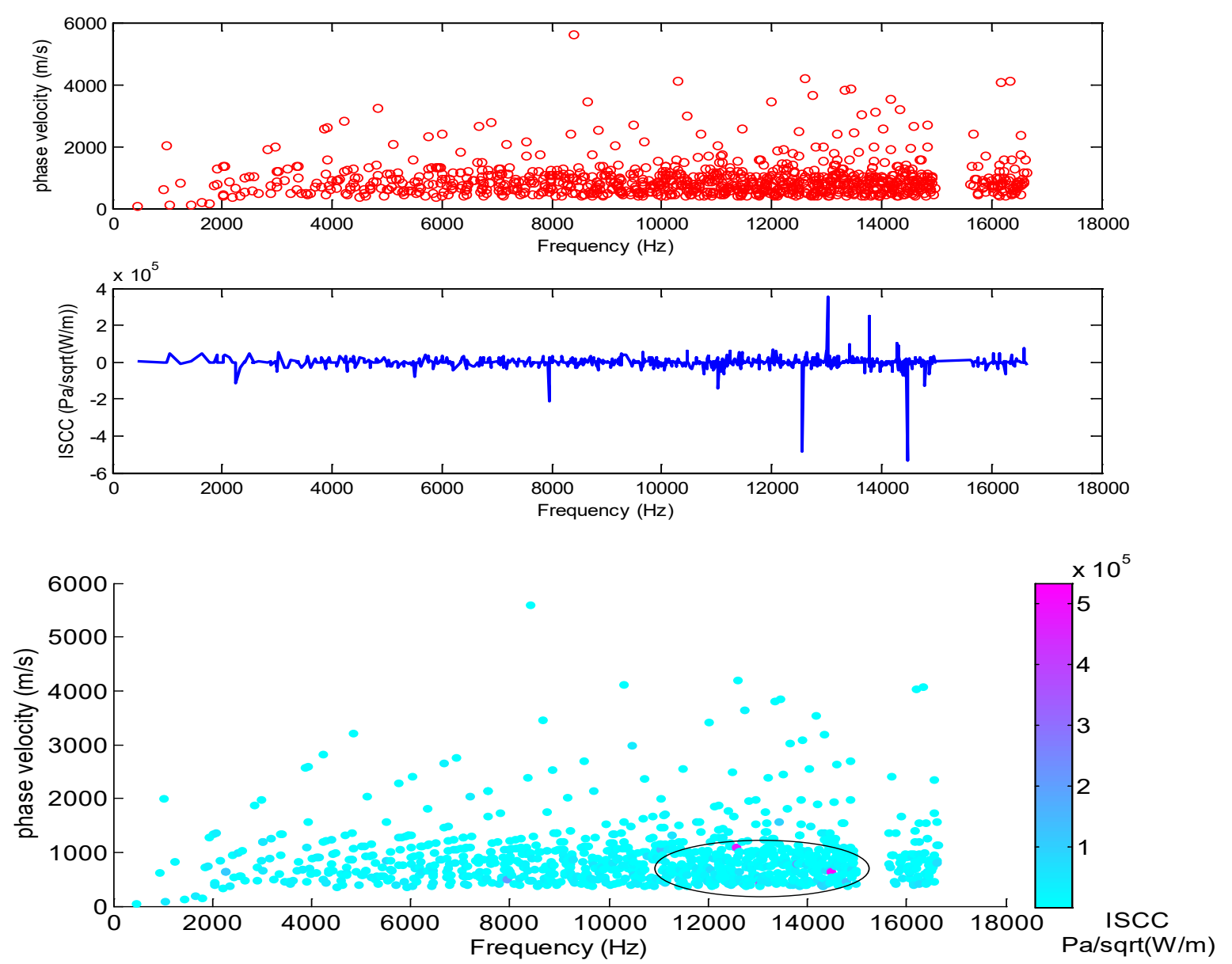

Fig. 4: Dispersion curve (above), ISCC curve (mid), Combination of dispersion curve and ISCC curve (below) for the blade with $2 \mathrm{~mm}$ thick glaze ice to find non-dispersive modes of high ISCC indicated by circled area

A sine wave was used for excitation of transducers. The transient distribution of stress and displacement could then be calculated. The model to be investigated was a composite blade with $7 \mathrm{~mm}$ thickness at the leading edge covered by a $2-\mathrm{mm}$ thick ice layer. According to the data given in Table 2, the central frequency was set to $12.56 \mathrm{kHz}$, and the wave length $\lambda=0.1667 \mathrm{~m}$. The pair of transducers was placed $\lambda / 4$ apart on the leading edge, as shown in Fig. 5 , to enhance each other. The displacement and stress distribution at different times are shown in Figs. 6 and 7. According to the figures, the ultrasonic wave was guided and the power was concentrated on the leading edge of the blade, gradually propagating to the other parts of the blade. 

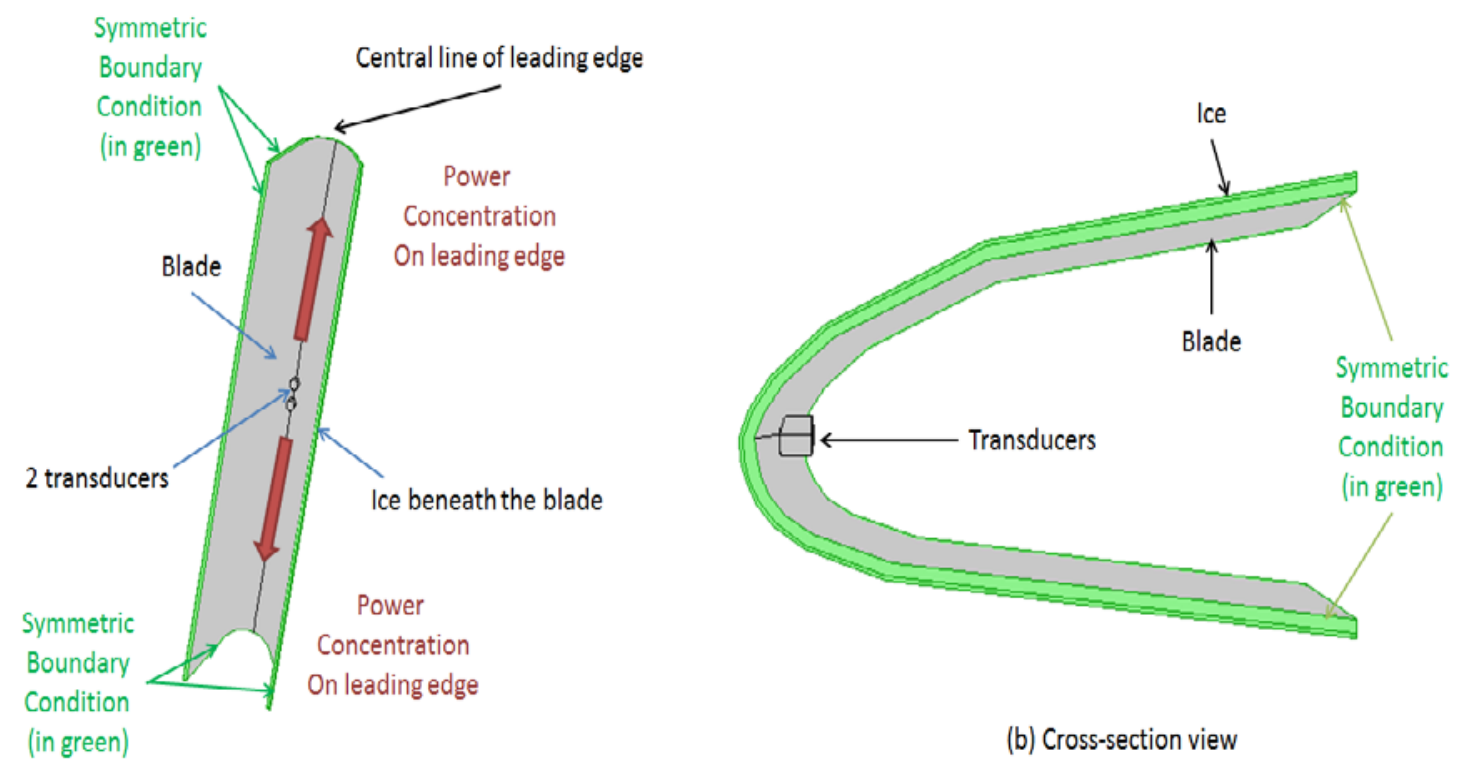

(a) $3 D$ view

(b) Cross-section view

Fig. 5: Configuration of two transducers on the leading edge of the blade
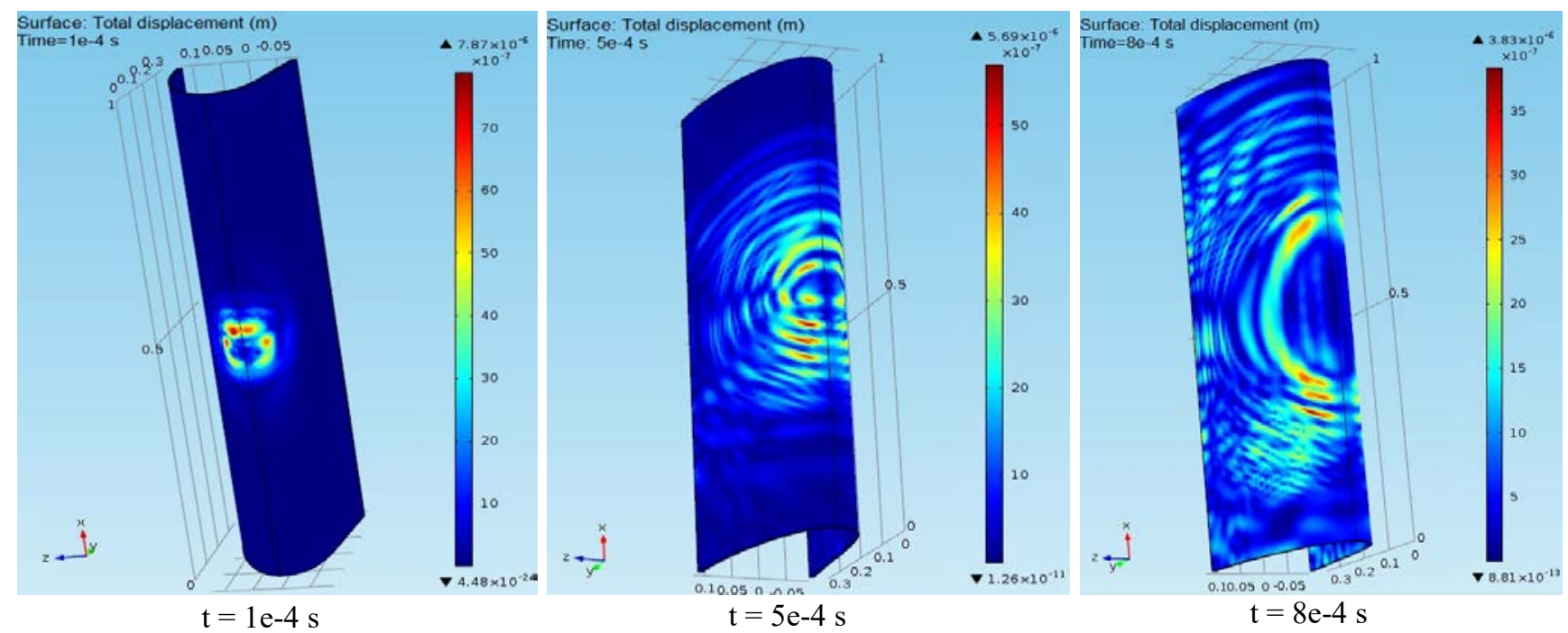

Fig. 6: Displacement distribution in the composite blade over time with 2-mm thick ice showing wave propagation and coverage across $1 \mathrm{~m}$ of the leading edge at $\mathrm{t}=100 \mu \boldsymbol{s}, \mathrm{t}=500 \mu \boldsymbol{s}$ and $\mathrm{t}=800 \mu \boldsymbol{s}$ 


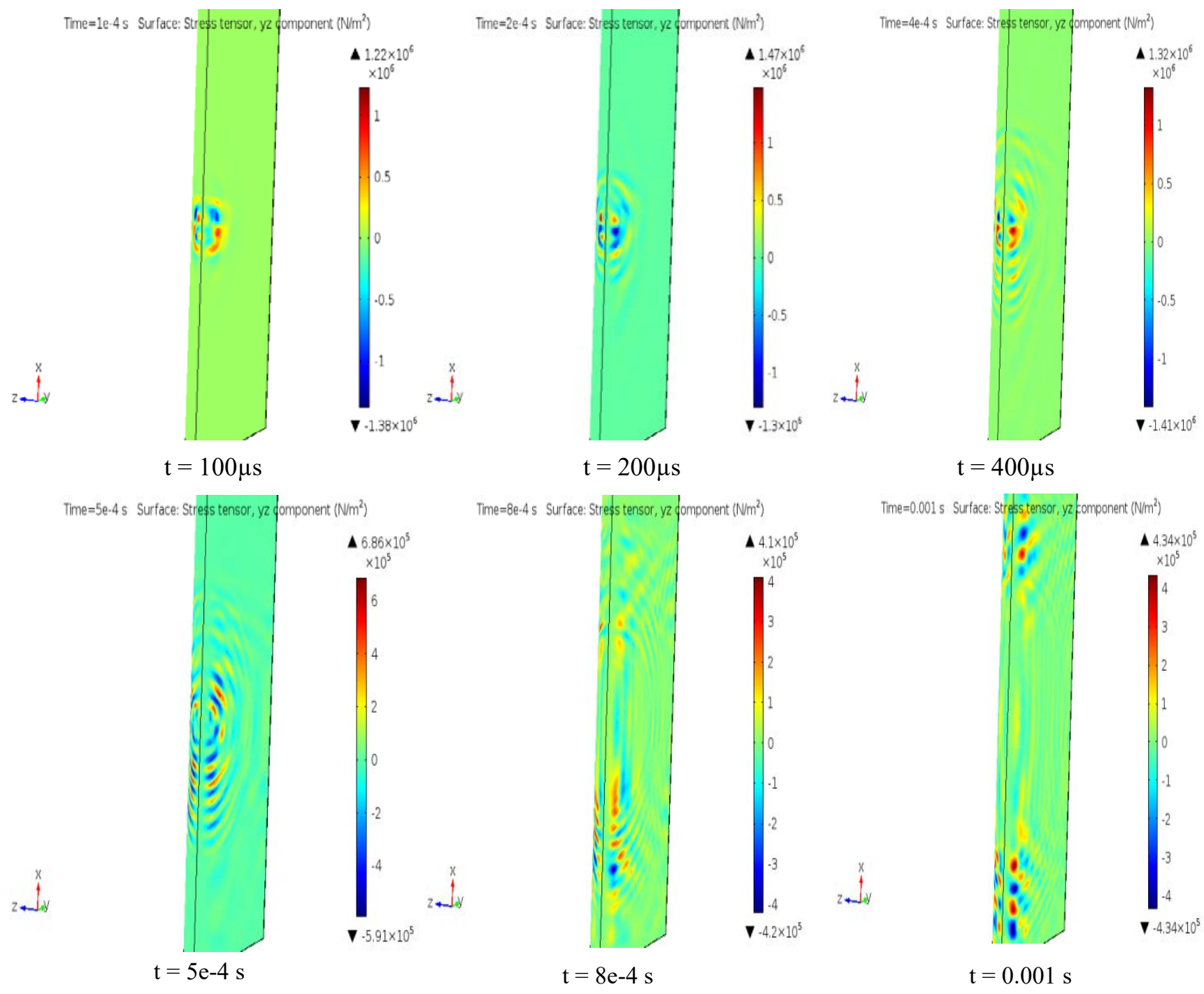

Fig. 7: Distribution of the shear stress component $\sigma_{\mathrm{yz}}$ at the interface of ice and GFRP in the leading edge of the composite blade over time with 2-mm thick ice showing wave propagation and coverage across $1 \mathrm{~m}$ of the leading edge from $\mathrm{t}=100 \boldsymbol{\mu}$ s to $\mathrm{t}=1 \mathrm{~ms}$.

Finally, the distribution of displacement and stress for the GFRP blade's leading edge were calculated. A pair of transducers along with fibre orientation was designed to additively enhance the induced energy, achieving power concentration at the leading edge. The effective stress domain induced at the blade varied from 0.4 to $2 \mathrm{MPa}$ which is consistent with the criteria given by previous experimental tests on composite material [22-24] for removing glaze ice. The power input was applied in form of force per unit area (selected to be $1 \mathrm{MN} / \mathrm{m}^{2}$ in this case as an optimum value) on the transducers. To obtain this, a series of simulations was conducted with increasing orders of input load for two transducers from 1Pa to $10 \mathrm{MPa}$ to investigate a range of values. As a result, when the input loads reached $1 \mathrm{MPa}$, the effective shear stress at the interface of blade and ice achieved the criteria range $(0.4-2 \mathrm{MPa})$. Figures 7 show that the arrangement is able to generate sufficient stress at the blade's edge to remove the ice. It should be noted that the occurrence of matrix failure or glass fibre failure under these conditions, has been well investigated both experimentally and theoretically $[4,5,8,13]$. Additionally, for more clarity, studies carried out by Zhao et al [25] showed that the levels of shear stress required to delaminate unidirectional glass fiber-epoxy composite are from $25 \mathrm{Mpa}$ to $72 \mathrm{Mpa}$ due to different surface treatments while, according to Figs. 7, the maximum shear stress induced at the leading edge does not exceed 1.5 MPa. 
To estimate the power consumption involved, suppose a couple of piezoelectric transducers, each of $1-\mathrm{cm}^{2}$ attachment area and 1-mm oscillating amplitude are utilised within the required time of $0.001 \mathrm{~s}$ for each metre of blade as suggested by the simulation results. The power for each transducer is calculated as $100 \mathrm{~W}$. To provide de-icing for the first 4 meters of the blade (which must be covered to compensate for the limitations of low-frequency vibration as noted in Section 3.2), 8 transducers then will be needed, i.e. $800 \mathrm{~W}$ for each blade. With installation of the transducer array on all three blades of the wind turbine, $2400 \mathrm{~W}$ would be the total necessary power for a $75 \mathrm{~kW}$ wind turbine which is $3.2 \%$ of the turbine's nominal power output. This value is a considerable reduction in required power for an ice protection system, compared to the power consumed by existing thermal de-icing methods which reach around $12 \%$ to $15 \%$ [2].

\subsection{Low-frequency vibrations}

The first modes are usually dominant in a frequency or time-domain response of a system (see Fig. 11). Hence the first three natural frequencies of the two models are shown in Table 3 although in the frequency range of [0-50] Hz, 7 modes were identified.

Table 3: Comparison of the developed blade with the similar one from a different work ([10]).

\begin{tabular}{|c|c|c|c|}
\hline \multirow{2}{*}{$\begin{array}{c}\text { Mode } \\
\text { number }\end{array}$} & Mode shape & \multicolumn{2}{|c|}{ Natural frequency (Hz) } \\
\cline { 3 - 4 } & Current model & Reference \\
\hline 1 & First flap-wise bending & 2.20 & 2.28 \\
\hline 2 & First edge-wise bending & 3.81 & 3.83 \\
\hline 3 & Second flap-wise bending & 10.39 & 8.25 \\
\hline
\end{tabular}

These results imply that the two models, at least in the lower frequencies, which have most contribution into the dynamics of system, are sufficiently consistent. In addition, the correspondent mode shapes at these frequencies had a similar trend to those presented in the reference. The third and fifth mode shapes, for example, are shown in Fig. 8 upon which the total displacement spectra are displayed. Modal analysis was also used for harmonic analysis to determine best potential locations for mounting shakers and applying vibratory forces. This corresponds to a few kinematic factors such as superposition of mode shapes, maximum displacements and nodal points in each mode shape as described below.

The schematic curves of the $1^{\text {st }}, 3^{\text {rd }}$ and $5^{\text {th }}$ mode shapes, based on the modal results are shown in Fig. 8. All of these correspond to bending flexural modes in direction $y$. Note that the displayed deflections are exaggerated. Since the second and forth modes have the same shape as the first and third modes but in direction $x$, they are not shown in this diagram. The largest deflection in all flexural bending modes was found to occur at the blade's tip. For this reason, point 3 in Figs. $3 \& 9$ is a location of top priority to be considered for mounting one of the shakers to excite the blade. Although the third and fifth modes do not have too much contribution to dynamical response they have to be considered in overall dynamic performance. They both have nodes (zero displacement) at point $\mathrm{C}$. To this extent, point $\mathrm{C}$ should not be a potential location for a shaker as generally it would not excite the correct mode at this nodal point and consequently not cause effective acceleration. There is another node at point $\mathrm{B}$ in the $5^{\text {th }}$ mode while the other two modes also have no large displacement at this point. In the vicinity of point $\mathrm{B}$, point 2 has considerable displacement in all the three modes which makes it a significant location to excite the mode shapes and vibrate the blade. 


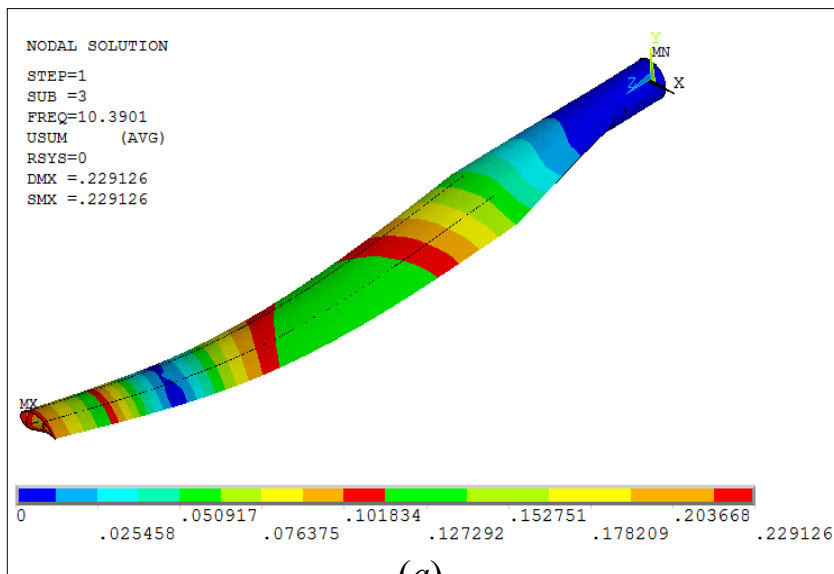

(a)

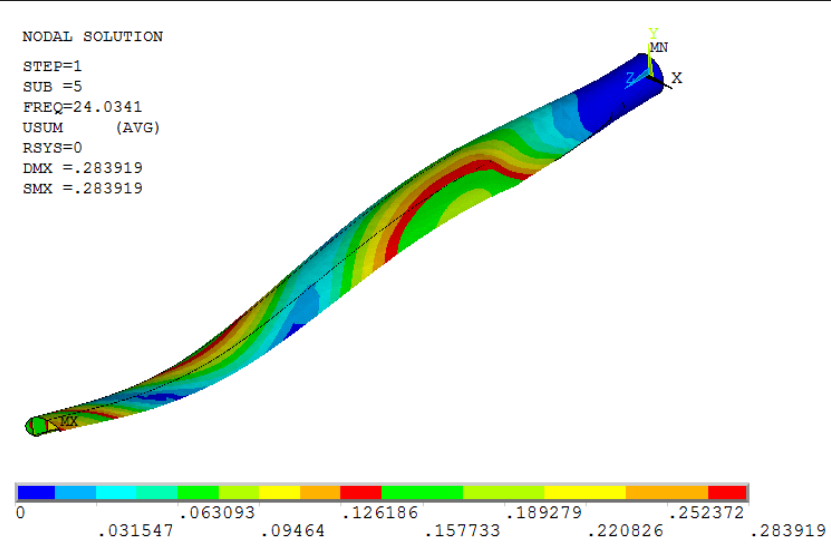

(b)

Fig. 8: The third and fifth mode shapes of the developed blade model

Another choice for mounting a shaker is point 1 because it seems to have almost same effect on all three modes for vibrating the system. Hence the three points 1,2 and 3 are the best candidates to configure an optimum array for shakers.

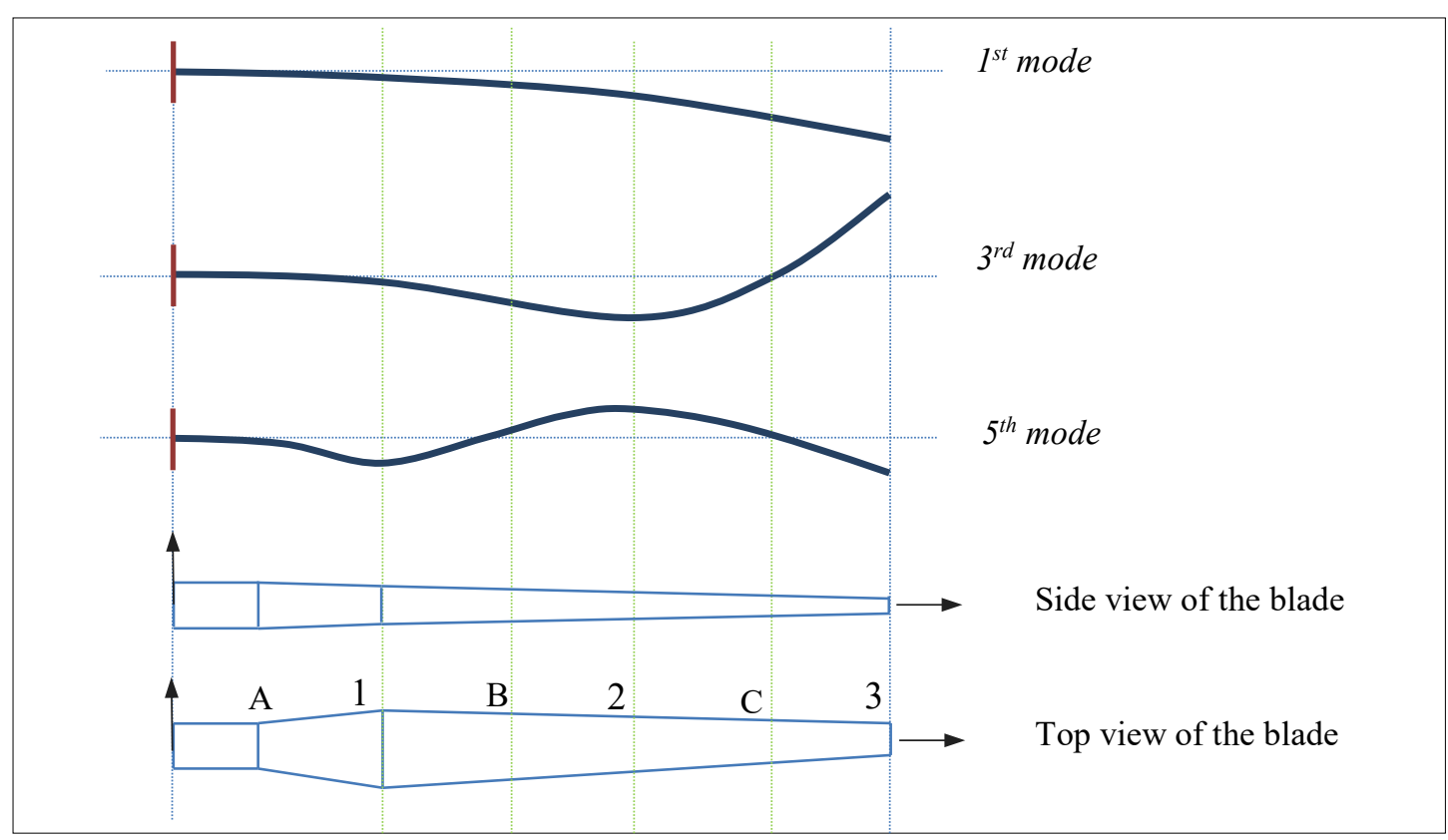

Fig. 9: Flexural bending mode shapes of the blade in direction $y$

As already mentioned, the aim of using low-frequency vibration is to cause sufficient acceleration on the whole blade's surface (and not only the leading edge) for removing ice. For this reason was necessary to identify the frequency at which maximum acceleration occurred. The amplitude of acceleration depends on two factors; displacement of the blade's surface and the frequency of forced oscillations. In this regard a survey was carried out to characterise maximum acceleration for two different types of mode i.e. Flapwise (flexural bending mode in direction $y$ ) and Edgewise (flexural bending mode in direction $\mathrm{x}$ ). Figures 10(a \& b) show the accelerations of three points of the blade indicated in Fig. 7 versus excitation frequency within [0 - 50] Hz using the full method of harmonic analysis, in the edgewise and flapwise modes. In this state, one shaker was applied on point 1. Figure 10(a) shows that maximum acceleration occurred at the 4th mode, $21.18 \mathrm{~Hz}$, which is the second flexural bending mode in the edgewise direction. Also Fig. 10(b) shows that the excitation frequency of maximum acceleration in direction y was the 6 th mode, $24.89 \mathrm{~Hz}$, which is the first torsion mode. So these two modes 
$(21.18 \& 24.89 \mathrm{~Hz})$ are the optimum frequencies in which required acceleration can be induced depending on the locations of shaker(s).

Figure 11(a) shows displacement of the blade's tip in three directions $x, y$ and $z$ due to a forced vibration in both $x$ and $y$ directions over a harmonic analysis of frequency range [0-50 $\mathrm{Hz}$. Accordingly Fig. 11(b) shows the corresponding von Mises stress values of a potentially critical element near to the blade root. The von Mises stress is usually used to check the possible failure of a material subjected to loading. It can be understood from Figure 11(b) that any possible failure due to a typical cyclic load is most likely to take place at $2.2 \mathrm{~Hz}$ which is the first resonant frequency of the system.

Consequently, as seen in Fig. 11(b), the frequency range at which maximum accelerations occur $(21.18 \& 24.89 \mathrm{~Hz})$ compared to the critical frequency range $(2.2 \& 3.8 \mathrm{~Hz})$, generates only small stresses and displacements. According to the results of harmonic analysis calculated from all 7 loading scenarios (i.e. dual shakers at points $1 \& 2,1 \& 3$ and $2 \& 3$; single shakers and triple shakers at all three points simultaneously), the peak von Mises stresses are all found at the first predominant natural frequencies in $x$ and $y$ directions $(2.2 \& 3.8 \mathrm{~Hz})$. In other words the frequencies beyond the second mode have little effect in reducing blade fatigue life due to the low stress experienced. This point has been also shown by other works on fatigue analysis of the turbine blades $[10,26]$. For this reason, a safe fatigue evaluation would be the one established on the basis of the first mode even though the optimum frequency for de-icing is the higher mode at $24.89 \mathrm{~Hz}$.
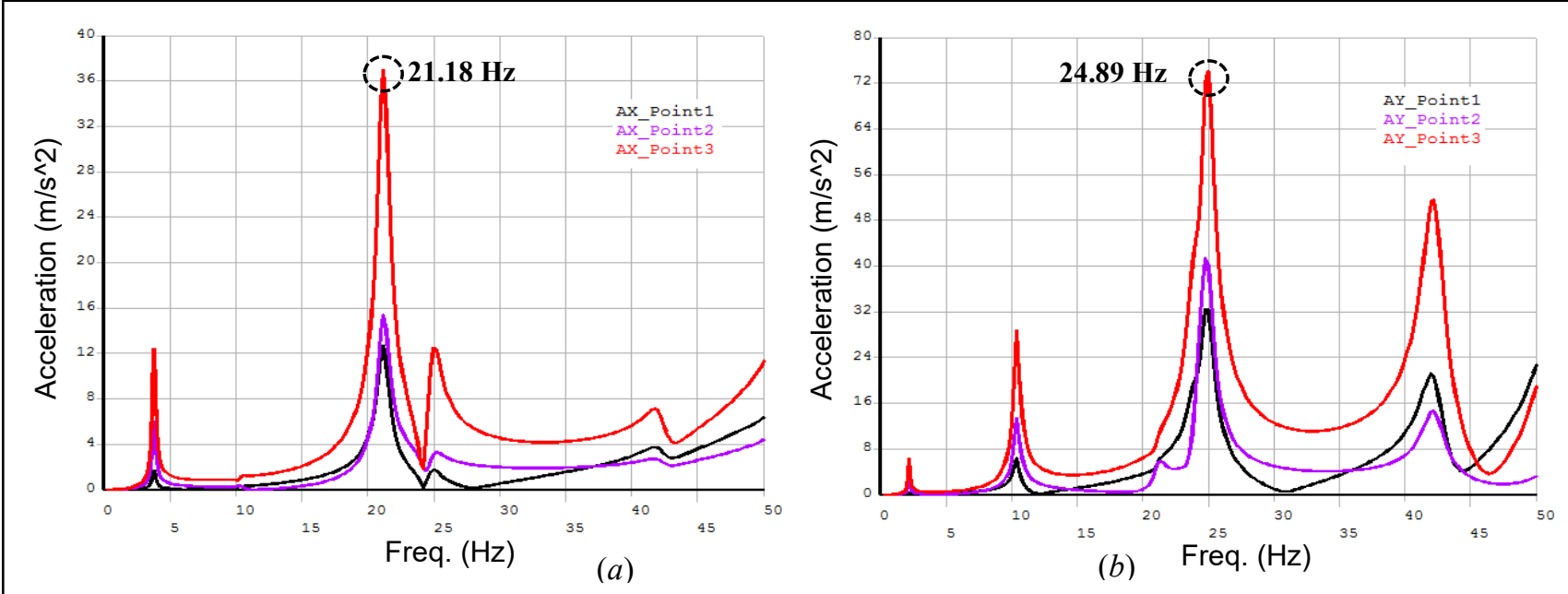

Figure 10: Acceleration, $\left(\mathrm{m} / \mathrm{s}^{2}\right)$, induced in the blade calculated for three different points of the blade in the frequency range $[050] \mathrm{Hz} ; a$ ) Edgewise direction $b$ ) Flapwise direction 
462

463

464

465

466

467

468

469

470

471

472

473

474

475

476

477

478

479

480

481

482

483

484

485

486

487

488

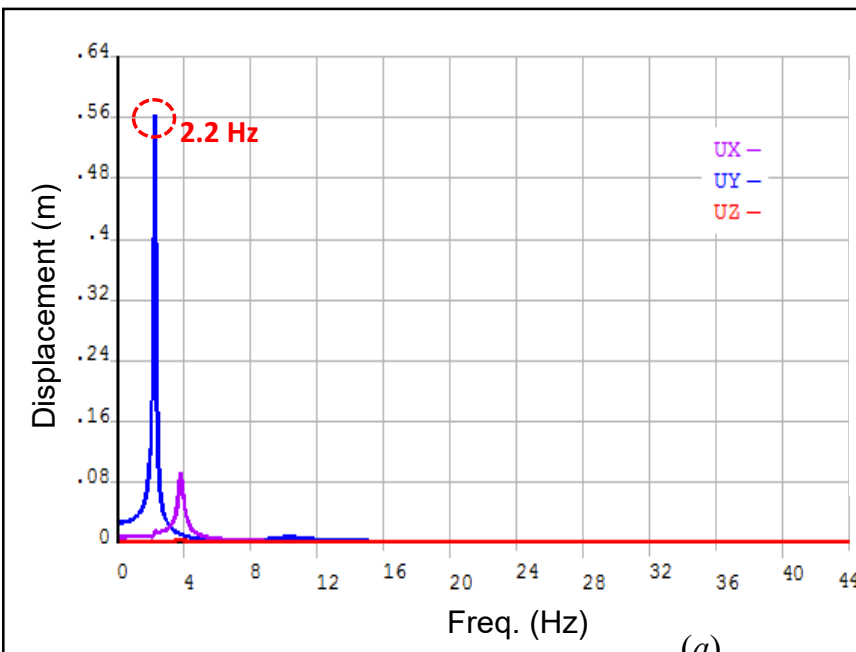

(a)

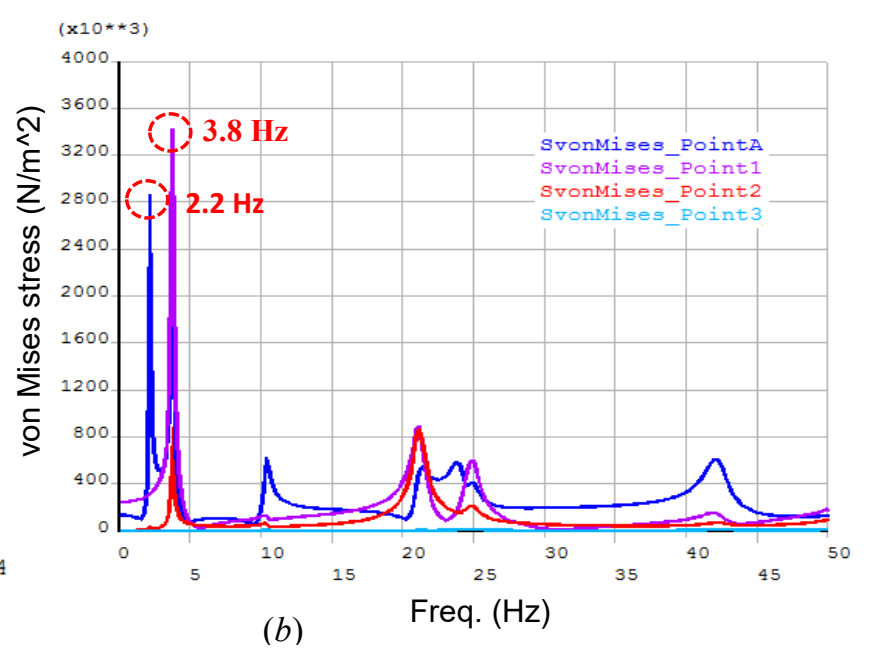

(b)

Fig. 11: The response of the blade subjected to forced vibrations a) Displacement of the tip in three directions $\mathrm{x}, \mathrm{y}$ and $\mathrm{z}, b$ ) von Mises stress calculated at four different locations of the blade (points A, 1, 2 and 3 as marked in Fig. 9) versus frequency

Table 4 summarizes the maximum values of displacement and acceleration occurring in the three different points of the blade $(1,2 \& 3)$ at the optimum frequency (i.e $24.89 \mathrm{~Hz})$ when the $100-\mathrm{N}, x-y$ harmonic forces are applied at these three points simultaneously. Comparing the displacements at three points, it can be seen that maximum accelerations of the blade in flapwise and edgewise directions both appeared at the end of the blade. The acceleration is more than $25 \mathrm{~g}$ at the points $2 \& 3$ which is sufficient to de-ice the blade according to the preliminary experimental tests [9]. This means that the induced vibration at point 1 could weaken the ice/substrate bond but for full de-icing, vibration should be complemented by the use of ultrasonic transducers. In other words, the distance between point A and point 2 in the blade which is almost 4 meters (see Figs. 3 \& 9) must be covered by guided waves through mounting one pair of transducers per one meter of the blade (according to the US wave results). The other potential scenarios for mounting shakers were found to be ineffective for generating enough acceleration for de-icing as they did not match the acceleration criteria. For this reason only the results corresponding to the successful scenario have been shown in Table 4.

Table 4: Displacement and acceleration induced in the blade at the frequency of $24.89 \mathrm{~Hz}$ when all three points are excited simultaneously

\begin{tabular}{|c|c|c|c|c|}
\cline { 2 - 5 } \multicolumn{1}{c|}{} & \multicolumn{2}{|c|}{ Displacement $(\mathrm{m})$} & \multicolumn{2}{c|}{ Acceleration $\left(\mathrm{m} / \mathrm{s}^{2}\right)$} \\
\hline Point 1 & $\begin{array}{c}\text { Edgewise direction } \\
\text { (X-axis) }\end{array}$ & $\begin{array}{c}\text { Flapwise direction } \\
\text { (Y-axis) }\end{array}$ & $\begin{array}{c}\text { Edgewise direction } \\
\text { (X-axis) }\end{array}$ & $\begin{array}{c}\text { Flapwise direction } \\
\text { (Y-axis) }\end{array}$ \\
\hline Point 2 & 0.0347 & 0.0464 & 81.615 & 218.685 \\
\hline Point 3 & 0.1257 & 0.3305 & 121.642 & 252.966 \\
\hline
\end{tabular}

In order to know whether or not the resonant vibration induced by the shakers could damage the structural integrity of the blade, the areas undergoing maximum stress, i.e. critical points of the blade, were identified through stress distribution in harmonic analysis. The first and second natural frequencies, $2.20 \mathrm{~Hz}$ and $3.81 \mathrm{~Hz}$ were the predominant, critical frequencies. Therefore, the maximum stresses created by harmonic loading at these two frequencies were investigated to form a basis for fatigue analysis of the blade.

Figure 12a shows the distribution of the principal shear stress $\left(\tau_{12}\right)$ upon the blade with a shaker placed at the blade's tip (point 3 in Figs. $3 \&$ 9) when $f=2.2 \mathrm{~Hz}$. Correspondingly the 
distribution of von Mises stress upon the blade while it is excited at the second natural frequency $(f=3.8 \mathrm{~Hz})$ has been captured and shown in Fig. $12 \mathrm{~b}$.

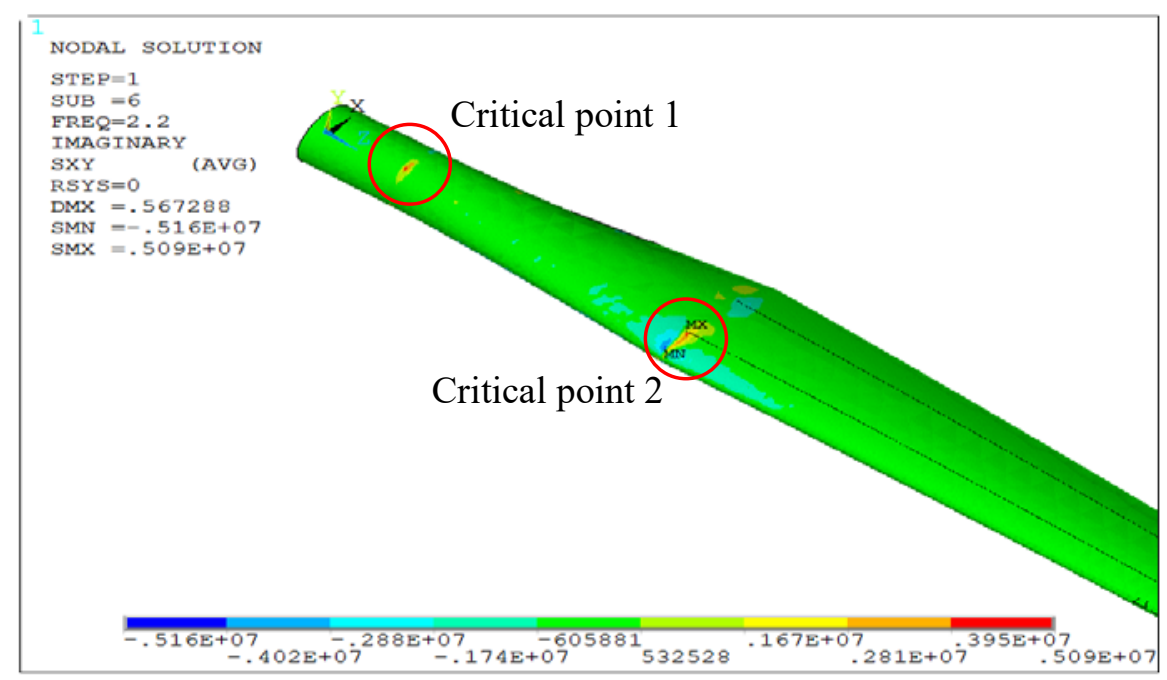

(a)

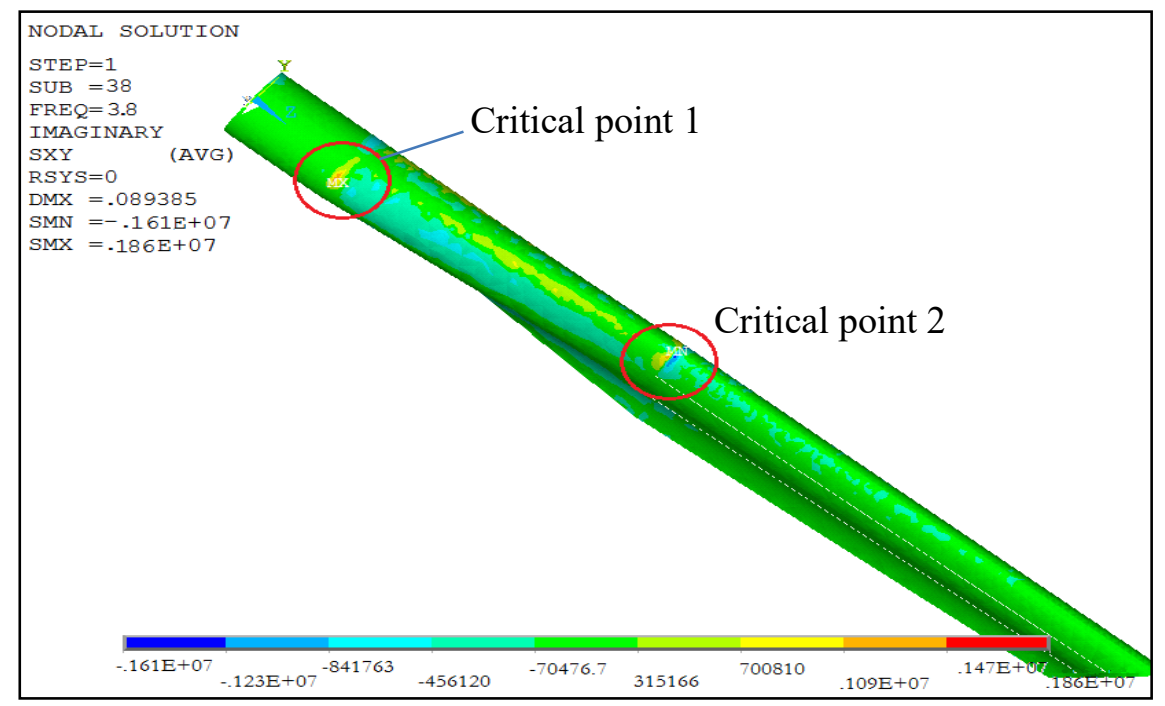

(b)

Fig. 12: Stress distribution upon blade due to a 100-N harmonic force applied at the blade's tip; $a$ ) shear stress when $f=2.2 \mathrm{~Hz} b$ ) shear stress when $f=3.8 \mathrm{~Hz}$. Critical pointes are circled.

The two areas marked by red circles in Fig.12 are critical (labelled as A \& 1 in Fig. 9). These two areas are critical at almost all the natural frequencies of the blade when they are excited. The higher stresses at these two areas are caused by 1) the large bending moment near to the blade root and 2) the change in smoothness and tilt of the blade geometry at the second critical area which increases the stress concentration coefficient.

\subsection{Fatigue life}

Different possible scenarios in terms of loading arrangement were considered in the analysis and approximate fatigue life in each case was derived and presented. In each case, the three stress values i.e. $\sigma_{1}, \sigma_{2}$ and $\tau_{12}$ had to be calculated. For example, considering point 1 , shown in Fig. 9, as the critical point, the maximum values were $\sigma_{1}=31.4 * 10^{6} \mathrm{~N} / \mathrm{m}^{2}, \sigma_{2}=15.2 *$ $10^{6} \mathrm{~N} / \mathrm{m}^{2}$ and $\tau_{12}=2.81 * 10^{6} \mathrm{~N} / \mathrm{m}^{2}$ which consequently led to $N_{f}=1.42 * 10^{7}$ cycles. Similar calculations and considerations were performed for other scenarios of shaker arrays. All these 
results have been summarised in Table 5. Two samples of stress distributions upon the blade have already been shown in Fig. 12(a\&b). The data given in Table 5 show that most of the fatigue life cycles are within the acceptable range mentioned in section $2.5\left(10^{5}\right.$ to $10^{8}$ cycles for a standard life of the blade [17]). However, it is worth noting that since vibrators only operate for a very short time in each activation (roughly $2 \mathrm{sec}$ ), this number will correspond to a much longer period than the turbine life standard (20 year) for normal operating cycles under wind loading.

Note that the calculated $N_{f}$ here, has not considered the effects of normal operating cycles directly and only involves the effect of applying harmonic forces by low frequency vibrations. The fatigue analysis was based on the critical mode shape of the blade i.e. the first mode $(2.2 \mathrm{~Hz})$ as one of the conditions for using the original fatigue approach (Eq. 12). In this dominant mode, the blade always experiences maximum stresses and displacements. On the other hand the largest acceleration required for removing ice was found to occur at higher modes $(24.89 \mathrm{~Hz})$ which should be selected as the operational frequency. This reduces the danger of structural damage because the higher frequency not only ensures ice removal by inducing the largest acceleration but also decreases the stress compared to the dominant frequency $(2.2 \mathrm{~Hz})$ which consequently leads to significant increase in fatigue life values given in Table 5.

Table 5: summary of predicted fatigue life due to applying shakers of different positions (arrays) on the blade in its first natural frequency

\begin{tabular}{|c|c|c|c|c|c|c|c|}
\hline $\begin{array}{c}\text { Shaker(s) } \\
\text { arrangement }\end{array}$ & $\begin{array}{c}\text { Single } \\
\text { Point 1 }\end{array}$ & $\begin{array}{c}\text { Single } \\
\text { Point 2 }\end{array}$ & $\begin{array}{c}\text { Single } \\
\text { Point 3 }\end{array}$ & $\begin{array}{c}\text { Dual points } \\
1 \& 2\end{array}$ & $\begin{array}{c}\text { Dual points } \\
1 \& 3\end{array}$ & $\begin{array}{c}\text { Dual points } \\
2 \& 3\end{array}$ & $\begin{array}{c}\text { All points } \\
1 \& 2 \& 3\end{array}$ \\
\hline$N_{f}$ & $2.66 \mathrm{e} 15$ & $6.36 \mathrm{e} 9$ & $1.42 \mathrm{e} 7$ & $2.61 \mathrm{e} 9$ & $1.001 \mathrm{e} 7$ & $1.54 \mathrm{e} 6$ & $1.20 \mathrm{e} 6$ \\
\hline
\end{tabular}

\section{Concluding remarks}

A strategy has been developed to maximise the anti-icing/de-icing performance of a typical wind turbine blade. It consists of the combined use of ultrasonic guided waves which internally excite material particles and low-frequency vibrations to provide simultaneous external shaking of the whole structure of the turbine blade without compromising fatigue life. The two relatively efficient approaches combine to compensate for each other's deficiencies and collectively can provide a fully effective ice protection system.

Regarding the ultrasound technique on its own, dispersion curves and ISCC coefficients were calculated for an actual blade made from composite for the selection of wave mode and central frequency. The optimised central frequency, phase velocity and wave length of ultrasonic waves according to different situations including material and thickness of ice were determined. These outcomes provided guidance for the selection of frequency and wave mode for the design of transducer arrays. Investigation of allocated transducer arrays in order to focus energy and guide the waves led to selection and application of a pair of transducers in fibre orientation to generate sufficient shear stress on the leading edge for ice removal. Results showed that the ultrasonic wave was guided and power was concentrated on the central line of the blade leading edge, consuming considerably less power than existing thermal de-icing methods.

To investigate the structural response of the blade to forced vibration induced by shakers, a FEM model of the wind turbine blade was developed. The first 7 natural frequencies and mode shapes of the model were extracted and studied. Likewise the best potential points for mounting shakers were proposed as a result of modal analysis, based on superposing mode shapes and their nodes. This made it possible to characterize the optimum points and directions $(x$ and $y)$ at which the blade should be excited. In the following, harmonic analysis within a low frequency band ([0 
- 50] Hz) was performed to investigate the effects of forced vibration on the wind turbine blade. Different shaker arrays covering 7 loading states in total, consisting of single, double and triple arrangements, were considered. It was found that an optimum topology for the shakers is a threevibrator set-up i.e. the loading conditions in which all the three potential points are excited in both flapwise and edgewise directions. In this arrangement, the required acceleration for removing ice may be induced on the major surface of the blade, particularly the areas that cannot be covered by ultrasound waves. Also the critical stress values in each case were calculated for fatigue life prediction. The fatigue analysis showed that vibrating the blade at such frequencies complies with standards of composite blades regarding fatigue life. In fact, they all led to the tolerable loading cycles that do not apply any risk to the structural integrity of the blade.

It can be noted that the interaction between the rotating blade and the distortion due to vibrations can be a topic for future work, especially an analysis of the dynamical balancing of the turbine's blades. Future work will also concentrate on prototyping the developed system and experimental test rigs.

\section{Acknowledgements}

The DeICE-UT project is co-founded by the European Commission through the Seventh Framework Programme (FP7/2007-2013) managed by REA-Research Executive Agency through the funding scheme "Research for the Benefit of SMEs" under Grant Agreement No.605138.

\section{References:}

[1] Kimura S., Sato T., Kosugi K., The effects of anti-icing paint on the adhesion force of ice accretion on a wind turbine blade, Proceedings of BOREAS VI International Conference, April 2004, Finish Meteorological Institute, Pyhatunturi, Finland, pp. 9.

[2] Laakso T., Peltola E., Review on blade heating technology and future prospects, Proceedings of BOREAS VII International Conference, March 2005, Saariselka, Finland, pp. 12.

[3] Sørensen J.D., Sørensen J.N., Wind energy systems: optimising design and construction for safe and reliable operation, Woodhead Publishing Ltd., UK, 2011.

[4] Gao H. D., Rose J. L., Ice Detection and Classification on an Aircraft Wing with Ultrasonic Shear Horizontal Guided Waves, Ultrasonics, Ferroelectrics and Frequency Control, Vol. 56, Issue: 2, 334-344, 2009.

[5] Overmeyer A., Palacios J., and Smith E., Ultrasonic De-Icing Bondline Design and Rotor Ice Testing, AIAA Journal, Vol. 51, No. 12 (2013), pp. 2965-2976. doi:10.2514/1.J052601

[6] Nicola DiPlacido, Jared Soltis, Edward Smith, and Jose Palacios, The Pennsylvania State University, "Enhancement of Ultrasonic De-icing via Transient Excitation," The 2nd Asian/Australian Rotorcraft Forum and The 4th International Basic Research Conference on Rotorcraft Technology Tianjin, China, September 08-11, 2013

[7] Venna S., Lin Y., Botura G., Piezoelectric Transducer Actuated Leading Edge De-Icing with Simultaneous Shear and Impulse Forces, Journal of Aircraft, Vol. 44, No. 2, 509-515, 2007.

[8] Palacios J.L., Design fabrication and testing of an ultrasonic de-icing system for helicopter rotor blades, PhD Thesis, the Pennsylvania State University, Engineering Science and Mechanics, 2008. 
601

602

603

604

605

606

607

608

609

610

611

612

613

614

615

616

617

618

619

620

621

622

623

624

625

626

627

628

629

630

631

632

633

634

635

636

[9] Coffman H.J., Helicopter Rotor Icing Protection Methods, Bell Helicopter Textron Inc., Fort Worth Texas, Journal of the American Helicopter Society, 1987.

[10] Movaghghar A. and Lvov G.I., A method of estimating wind turbine blade fatigue life and damage using continuum damage mechanics, International Journal of DAMAGE MECHANICS, Vol. 21, 810-821, August 2012.

[11] Kong C., Bang J., Sugiyama Y., Structural investigation of composite wind turbine blade considering various load cases and fatigue life, Energy 30 (2005) 2101-2114

[12] Mahri Z. L. and Rouabah M. S., Fatigue Estimation for a Rotating Blade of a Wind Turbine, Rev. Energ. Ren., Vol.5(2002) 39-47.

[13] Palacios J., Smith E., Rose J. L., Gao H., Ultrasonic Shear Wave Anti-Icing System for Helicopter Rotor Blades,62nd Annual Forum Proceedings-American Helicopter Society, Phoenix, Arizona, 1492-1502, 2006.

[14] Johnston J.F., Farone W.A. and Mikhail A., Composite Wind Turbine Rotor Blade and Method for Making Same, US Patent No. 4976587, 1990.

[15] Larwood S. and Musial W., Comprehensive Testing of Nedwind 12-Meter Wind Turbine Blades at NREL, ASME Wind Energy Symposium, Reno, Nevada, January 2000.

[16] Aluminum Standard and Data, 1984, Eighth Edition, The Aluminum Association, Washington, DC, 1984.

[17] Sutherland H.J., On the Fatigue Analysis of Wind Turbines, Sandia National Laboratories, Albuquerque, New Mexico 87185-0708, June 1999.

[18] Creed R.F., Jr., High Cycle Tensile Fatigue of Unidirectional Fiberglass Composite Tested at High Frequency, M.S. Thesis, Dept. of Chemical Engineering, Montana State University, Bozeman, 1993.

[19] Mandell J.F., Creed R.J., Pan Q., Combs D.W. and Shrinivas M., Fatigue of Fiberglass Generic Materials and Substructures," Wind Energy 1994, SED Vol. 15, ASME, p. 207.

[20] Frohboese P., Anders A., Effects of Icing on Wind Turbine Fatigue Loads, Journal of Physics: Conference Series 75 (2007) 012061, (doi:10.1088/1742-6596/75/1/012061)

[21] Noda M., Flay R.G.J., A simulation model for wind turbine blade fatigue loads, Journal of Wind Engineering and Industrial Aerodynamics 83 (1999) 527-540.

[22] Ramanathan S., An Investigation on the Deicing of Helicopter Blades Using Shear horizontal Guided Waves" PhD Thesis, the Pennsylvania State University, Engineering Science and Mechanics, May 2005.

[23] Brouwers E., Palacios J., Smith E.C., The Experimental Investigation of a Rotor Hover Icing Model with Shedding, Journal of America Helicopter Society, 2010.

[24] Stallabrass J.R., Price R. D., On the Adhesion of Ice to Various Materials, Canadian Aeronautics and Space, 1963, 199-203.

[25] Zhao, F. M., Takeda, N., "Effect of Interfacial Adhesion and Statistical Fiber Strength on Tensile Strength of Unidirectional Glass Fiber/Epoxy Composites," Composite, Part A, pp. 1203- 1214, 2000.

[26] Eggleston DM, Stoddard FS. Wind turbine engineering design. New York: Van Nostrand Reinhold; 1978. 